\title{
Manejo exitoso de una inundación en el Herbario USJ de Costa Rica
}

\author{
Carlos O. Morales \\ Herbario Luis A. Fournier (USJ), Universidad de Costa Rica, 11501-2060 San José, Costa Rica; carlos.moralessanchez@ucr.ac.cr
}

Recibido 14-III-2013 Corregido 30-III-2013 Aceptado 29-IV-2013

\begin{abstract}
Successful management of water damage caused by a flood in the USJ Herbarium of Costa Rica. In November 2007 the break of a drink-water pipeline at the Biology Department, University of Costa Rica caused a flood in the USJ Herbarium and severely damaged many specimens that stayed wet for more than one week. Here I report on the actions that were taken to rescue and restore all the mounted and catalogued specimens that were damaged, and discuss several lessons that were learned from this incident.
\end{abstract}

KEY WORDS

Protection of scientific collections, Herbarium security, flooding, USJHerbarium, specimen restoration, Costa Rica

\section{RESUMEN}

En noviembre de 2007 se rompió una cañería de agua potable en la Escuela de Biología, Universidad de Costa Rica, que provocó una inundación que afectó seriamente el Herbario USJ. Aquí comento las lecciones aprendidas y las claves del rescate exitoso de todos los especímenes montados, que estuvieron húmedos incluso más de una semana.

\section{PALABRAS CLAVE}

Protección de colecciones científicas, seguridad en herbarios, inundación, Herbario USJ, reparación de especímenes, Costa Rica
En 2007, la ruptura de una cañería de agua potable provocó una inundación en el Herbario Luis A. Fournier (USJ), de la Universidad de Costa Rica. El objetivo de este texto es divulgar entre botánicos de Costa Rica y del extranjero las lecciones aprendidas, porque sin duda pueden ser útiles, tanto para prevenir como para realizar acciones prontas y apropiadas que impidan la pérdida irreparable de especímenes después de un accidente catastrófico.

El Herbario USJ fue fundado en 1931 en el Centro Nacional de Agricultura, antes de que existiera la Universidad de Costa Rica (Morales \& Villalobos, 2004; Morales, 2006; 2012). Al cumplir 76 años enfrentó un gran peligro que pudo significar el final de una de las colecciones científicas más grandes de América Central. Este herbario ya había sufrido los estragos de un incendio el 20 de marzo de 1965 (Barquero, 1982), cuando se perdieron unos tres mil especímenes y la mayor parte de la biblioteca (L.A. Fournier, com. pers., ca. 2000, R. Ortiz, com. pers., ca. 2002).
El incendio referido fue un error humano lamentable, porque la secadora de plantas estaba dentro del herbario, en un edificio viejo de madera. La inundación que nos ocupa ahora no fue un error de ese tipo, sino un fenómeno (la ruptura de una cañería oxidada) que pudo haber ocurrido en cualquier edificio de cualquier parte del mundo. La acción pronta de personas educadas y conscientes, que en lugar de llegar a cruzarse de brazos y a quejarse de una desgracia se pusieron a trabajar, hizo la diferencia entre un daño irreversible y uno que pudo controlarse. Las personas tienen que estar convencidas de que algo, en este caso una colección científica, es importante, para actuar de inmediato en defensa de su existencia y su integridad.

La inundación se debió a la ruptura de una cañería de agua potable en el laboratorio 220 , tercer piso del edificio de la Escuela de Biología, que ocurrió el domingo 25 de noviembre de 2007 por la noche; algunos consideran que pudo relacionarse con un sismo que ocurrió a las 20:40 horas, con una magnitud de 4,0 (escala de Richter), a 47,5 $\mathrm{km}$ de profundidad, con epicentro a $4 \mathrm{~km}$ al SE de Quepos, 
Puntarenas (RSN, 2007). El agua afectó la mitad del edificio y llegó hasta el sótano, donde está el herbario desde 1999. El día siguiente a las 7a.m. el agua había empapado los especímenes de varios puntos del herbario. En algunas partes caían goteras; en otras, chorros de agua. En la esquina SE del herbario había unos $4 \mathrm{~cm}$ de agua en el piso a las 8a.m. El agua que cayó a través de grietas del piso superior o de perforaciones de tuberías mojó ca. 20\% de las dicotiledóneas guardadas en un sistema compactador de seis gabinetes móviles (sensu Touw \& Kores, 1984). El material que estaba dentro de gabinetes metálicos tradicionales o de gavetas de madera bien cerradas no se mojó ni se dañó de ninguna manera.

Se reveló que el sistema compactador que alberga la colección de dicotiledóneas (Fig. 1), la más grande del herbario, no está asegurado contra fugas de agua en la parte superior, que pueden ser causadas por cañerías rotas, lluvia, huracanes, tornados o terremotos. Al cerrarlos, los gabinetes móviles no quedan herméticamente cerrados porque el techo es plano, cerrado sólo en los extremos del primero y del último gabinete. Allí donde se cierran los pasillos del compactador (Fig. 2) debería haber un canal inclinado que recoja las aguas que pudieran filtrarse a través del techo de la habitación. Técnicamente la solución parece sencilla, sobre todo si se coloca una canoa inclinada, complementaria entre cada par de gabinetes móviles.

Poco más de una semana después del accidente todavía había especímenes húmedos (en algunos casos, carpetas completas) en el compactador de dicotiledóneas. El Museo de Zoología y el Laboratorio de Entomología habían prestado cinco extractores de humedad, que se

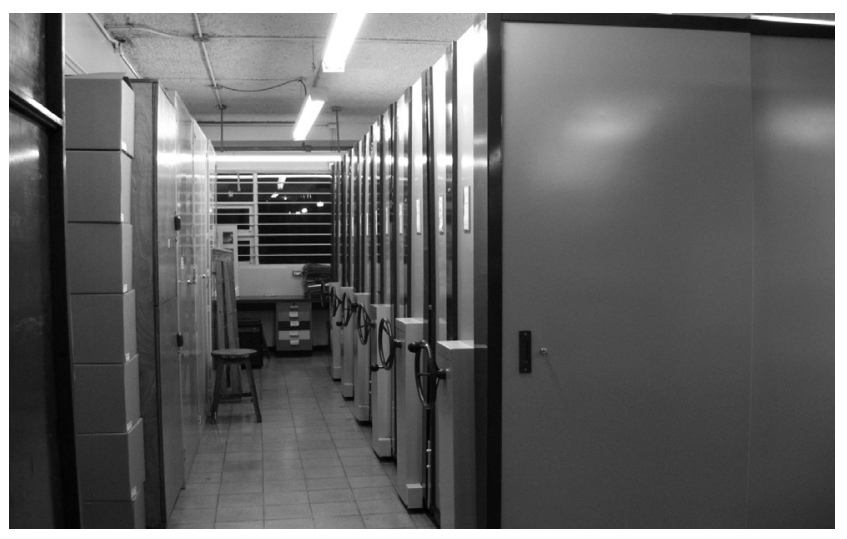

FIG. 1. Aspecto del sistema compactador (derecha) con la colección de dicotiledóneas del Herbario USJ.

Foto del autor, enero de 2013. mantuvieron trabajando día y noche junto al compactador en el que se halla la colección de dicotiledóneas, que fue la más afectada. Un extractor más se ubicó en el cuarto de montaje y dos en el área de no vasculares. Además, contamos con dos potentes aparatos de aire acondicionado en el área de plantas vasculares. Sin esta tecnología, que acelera extraordinariamente la extracción de la humedad excesiva, habría sido imposible recuperar todo el material científico humedecido.

En las colecciones de hongos, líquenes, algas y briófitos también cayó agua desde el techo, pero la cantidad fue mucho menor que en las colecciones vasculares, porque las primeras se hallan separadas de las vasculares por dos paredes, a unos $10 \mathrm{~m}$ del sitio de mayor impacto de la inundación. En general, en los grupos no vasculares sólo fue necesario cambiar sobres de papel y cajitas de cartón, en especial de varios taxa de hongos. Un punto crucial es el siguiente: Todo el material de grupos no vasculares se hallaba en gabinetes de metal de cierre hermético. Solamente en pocos casos, en que la cerradura de las puertas estaba dañada, pudo penetrar el agua.

Ni un solo espécimen vegetal montado y catalogado se perdió. No obstante, en el cuarto de montaje había material en proceso, guardado en cajas de cartón, fuera de gabinetes, que sí se perdió porque fue imposible ponerlo todo a tiempo en la secadora de plantas. Sin embargo, sólo se trataba de duplicados de material común (por ej., ningún tipo ni ejemplares únicos de especies raras) o de material sin importancia porque tenía varios años en espera de datos, que los recolectores nunca enviaron a USJ. La prioridad absoluta era salvar los especímenes montados y

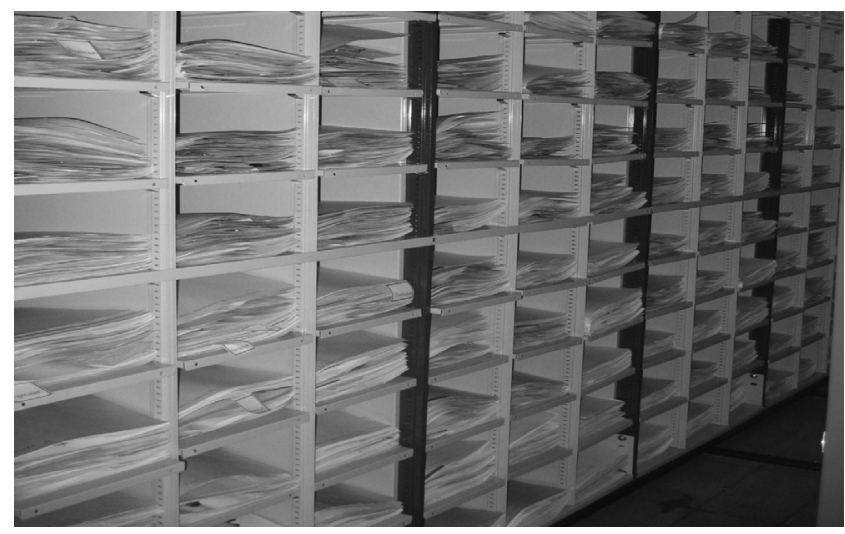

FIG. 2. Sistema compactador abierto para mostrar la organización en gavetas con carpetas de especímenes. Herbario USJ. Foto del autor, enero de 2013. 
catalogados que ya estaban integrados en la colección. El daño del agua que cayó directamente en las cajas de material en proceso, que se hallaban fuera de gabinetes, ilustra de modo contundente la importancia de tener todos los especímenes montados y catalogados, todos los especímenes más valiosos en proceso, además de tipos, unicata, préstamos y donaciones dentro de gabinetes de metal o madera bien cerrados y resistentes al agua (Metsger \& Byers, 1999, p. 175). Se comprobó que no se requiere de maderas finas; es más importante que la madera esté sana (sin grietas ni daño por termitas u hongos) y recubierta por una capa de pintura protectora y aislante. Así, por ej., numerosos especímenes prestados a USJ por otros herbarios se hallaban en las gavetas de madera de una mesa de trabajo; sobre una esquina de esta mesa cayó mucha agua durante horas, pero no entró ni una sola gota en las gavetas. Además, sobre dos gabinetes de metal cerrados cayó un pequeño chorro de agua durante horas; sobre el techo de cada gabinete se formó un pozo de agua que desaguó constantemente hacia atrás y delante del mueble, sin que entrara ni una gota en el interior, donde había numerosos especímenes prestados a USJ. Aparte de la protección del material científico, el equipo de cómputo y de óptica debe tener siempre cubiertas a prueba de agua y los libros y las revistas más valiosos deben mantenerse en estantes, gavetas o gabinetes cerrados y protegidos.

Numerosos estudiantes, profesores y personal administrativo prestaron una ayuda logística extraordinaria en el herbario, crucial en los momentos más críticos de la emergencia. Al empezar el trabajo de sacar toda el agua posible y recuperar los especímenes húmedos, para algunos la tarea parecía imposible; sin embargo, todas las personas que colaboraron durante las horas más críticas hicieron una gran diferencia. El resto fue un trabajo minucioso de separar, examinar y poner a secar varios miles de especímenes. Quince días después del accidente consideré concluidas las tareas de emergencia iniciadas en el herbario el 26 de noviembre de 2007. Fueron dos semanas de trabajo intenso y constante para poder salvar todos los especímenes que estaban ligera, mediana o severamente humedecidos.

Pese a que tuvimos cinco extractores de humedad y dos grandes aparatos de aire acondicionado funcionando día y noche durante dos semanas, sucedió lo más temible: varias decenas de especímenes, que permanecieron húmedos durante más de una semana, fueron atacados por hongos (Metsger \& Byers, 1999, p. 32). Las familias más afectadas fueron sobre todo Boraginaceae herbáceas y Brassicaceae. Un dato curioso es que los ejemplares de Heliotropium (Boraginaceae) estuvieron húmedos durante más de una semana sin ser atacados por hongos, pese a que muchas herbáceas alrededor sí fueron atacadas en condiciones idénticas, lo que parece sugerir que el material de este género conserva algún principio químico o físico que impide el crecimiento de hongos. En hojas gruesas y en tallos de ejemplares de plantas leñosas la formación de hongos fue a menudo nula o insignificante. Lo más satisfactorio de todo es que incluso el material herbáceo dañado fue salvado en su totalidad.

En este proceso se descubrió una técnica muy práctica y muy sencilla para recuperar especímenes vegetales atacados por hongos: Los especímenes montados se colocaron en una superficie sobre papel periódico, ligeramente inclinados hacia un lado; se tomó un recipiente de alcohol al 95\%, fácilmente manipulable, y se vació abundantemente sobre cada espécimen; de este modo los hongos fueron barridos del ejemplar vegetal, que quedó limpio en su mayor parte. Cuando un hongo había formado una costra sobre las hojas o alrededor de los tallos, se limpió el espécimen con una toalla de papel o un trapo untados de alcohol al 95\%. La técnica funcionó satisfactoriamente con tres tipos de hongos (distinguibles por los colores y la fisonomía o bien por el aspecto del ataque) e incluso cuando el ataque de hongos fue severo. Los especímenes así tratados se envolvieron en papel periódico seco (sobre todo para absorber el exceso de alcohol), se pusieron en una prensa con cartones, se llevaron a una secadora de plantas y en menos de 24 horas ya estaban secos. Once días después del accidente se trataron exitosamente con alcohol los últimos especímenes más afectados por hongos.

Dentro del herbario, después de superar la emergencia solamente habíamos cumplido la primera etapa de un proceso que implicó la restauración del material dañado: Sustitución de cientos de cartulinas y carpetas, desmontaje cuidadoso de los especímenes más dañados para ser montados en cartulinas nuevas, uso de goma y papel engomado en ciertos ejemplares cuando, por haber estado muy mojados durante horas o días, la goma y el papel engomado prácticamente se disolvieron, entre otros detalles. Un problema especial fue que las cartulinas muy mojadas de especímenes contiguos llegaron a pegarse en los extremos e incluso a fusionarse; normalmente esto no dañó el espécimen en sí, pero la separación tuvo que hacerse cuidadosamente, en especial para no perder información importante (número de herbario y datos de la etiqueta) ni causar daño en la muestra. Además, se comprobó que era mucho mejor separar los especímenes cuando las cartulinas todavía estaban húmedas, porque cuando estaban secas o casi secas era más probable la pérdida parcial o total de datos críticos (en especial si éstos no estaban incluidos en ninguna base de datos) y, quizás lo peor, en el ambiente cerrado de los especímenes se favoreció el crecimiento de hongos. Cabe señalar que la mayoría de 
especímenes dañados se restauraron solamente porque carpetas y cartulinas quedaron manchadas y retorcidas en los extremos, con daños mínimos o nulos en la muestra vegetal. Este trabajo de restauración puede iniciarse en cualquier momento después de que el material esté seco de nuevo (Fig. 3, 4 y 5). Once meses después del accidente ya se habían reparado todos los especímenes dañados; para esto se requirió de apoyo logístico y económico de la administración, tiempo, materiales apropiados y sobre todo personas bien entrenadas. Durante años he comprobado que, en general, las mujeres son más diestras y más pacientes que los hombres para realizar este tipo de tareas en el herbario.

Debe evitarse el uso de tintas de mala calidad (no permanentes) en etiquetas, sellos y números de herbario. En la mayoría de casos la tinta se diluye parcialmente, sin que se pierdan los datos, pero en algunos casos la tinta desaparece completamente, tanto en cartulina como en papel. No conviene el uso de tintas solubles de bolígrafos y plumas comunes ni la impresión electrónica de etiquetas de baja calidad. En años pasados, cuando se fumigaban directamente los especímenes con un insecticida líquido, también se diluían parcialmente las tintas no permanentes.

Clark (1986) explica la restauración exitosa de 32 especímenes de Rhus del Herbario K (Inglaterra), prestados a otra institución, que fueron severamente dañados por una inundación durante el viaje de regreso; al llegar a Kew estaban atacados por el moho ascomicete Trichoderma viride Pers. Estos especímenes fueron tratados con una solución de cloruro de mercurio y puestos en un congelador para desinfectarlos. Posteriormente se removió el papel de montaje y cada espécimen se montó de nuevo. Ella comprobó que varios tipos de papel usados tradicionalmente en Kew para montar especímenes y sobre todo para hacer etiquetas no son resistentes al agua; tampoco son apropiados ciertos materiales y compuestos usados para pegar. Igual que en USJ, Clark notó que ciertos tipos de tinta prácticamente se diluyen al contacto con el agua. Ella valora el uso de tintas de impresión resistentes, con base en carbón, y señala que la escritura con lápices de grafito es muy duradera. En USJ se usó grafito durante décadas para anotar nombres de especies en carpetas de cartulina manila y, en ocasiones, también para escribir etiquetas de papel. Sin embargo, dos o tres décadas después la escritura con grafito se volvió cada vez más borrosa hasta llegar a ser ilegible, probablemente en estrecha relación con el deterioro del papel y de la cartulina, que se acelera en contacto con agua.

En Ocean Springs, Misisipi (EE. UU.), el Herbario Pullen (MISS), que cuenta con unos 62000 especímenes

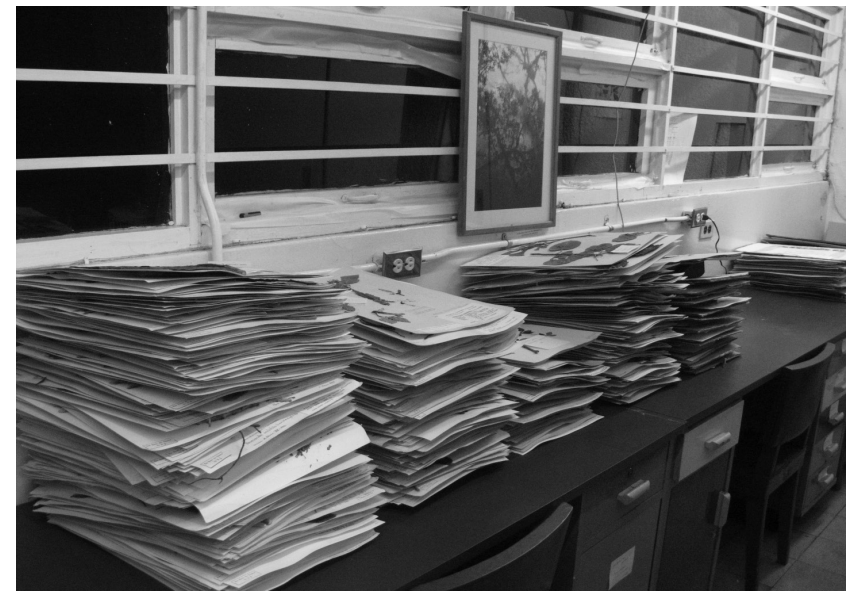

FIG. 3. Pilas de ejemplares de dicotiledóneas secos, después de haber estado en una secadora de plantas, listos para ser reparados. Herbario USJ.

Foto del autor, julio de 2008.

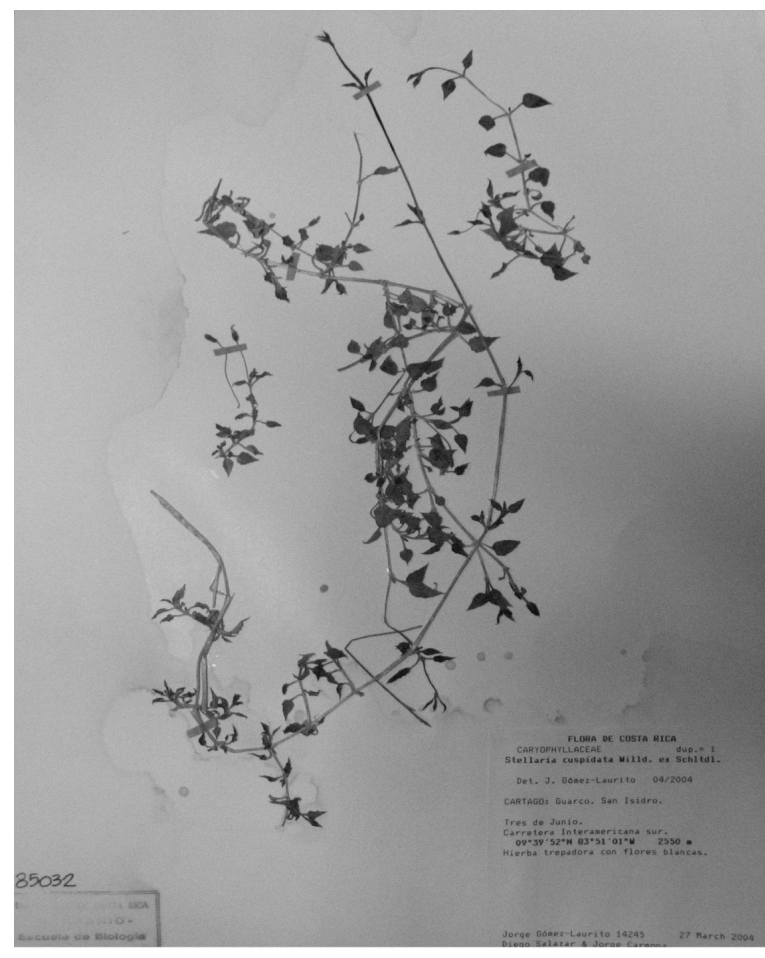

FIG. 4. Ejemplar que muestra el daño más común causado por el agua: manchas de agua sucia en la cartulina. Herbario USJ. Foto del autor, julio de 2008 


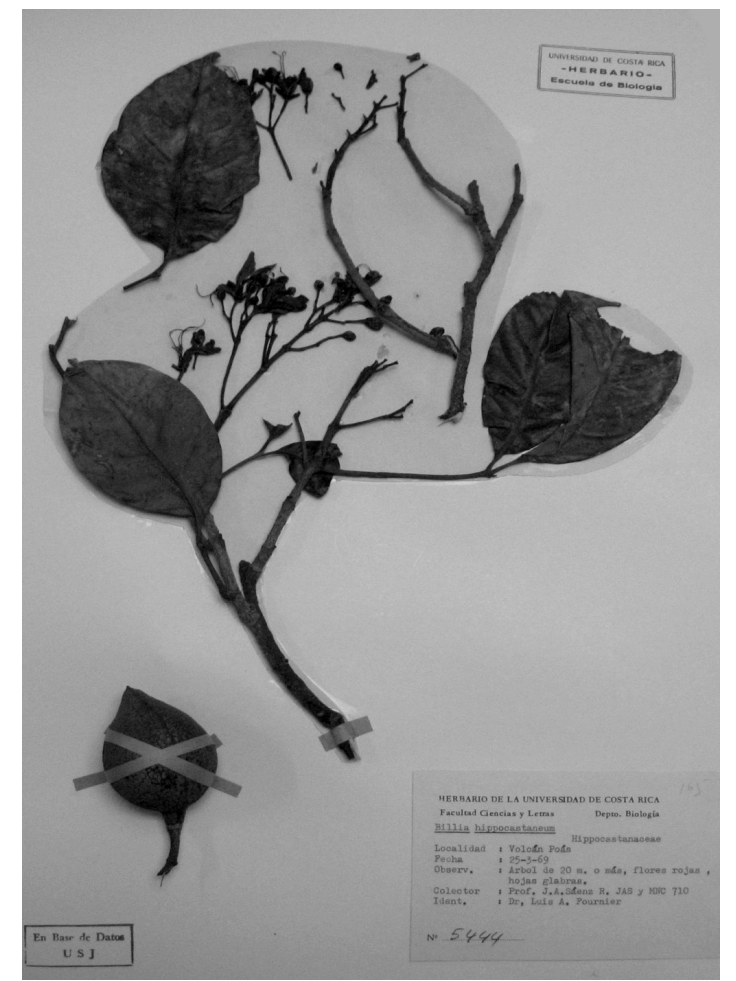

FIG. 5. Aspecto de un ejemplar reparado. La cartulina original dañada fue recortada cuidadosamente y sustituida en gran parte por una nueva. Herbario USJ.

Foto del autor, julio de 2008.

de plantas y otros grupos, fue severamente dañado por el huracán Katrina en agosto de 2005. Allí se organizó un proyecto de restauración, que consistió primero en conformar un equipo de trabajo, que incluyó voluntarios. Los gabinetes caídos debieron primero levantarse y colocarse en posición vertical. Parte del material más valioso en términos de conservación regional fue enviado a la Universidad Estatal de Luisiana. Dos personas examinaron el material de los gabinetes, lo separaron y rotularon según su estado: seco, húmedo, húmedo y enmohecido, empapado, empapado y enmohecido, etc. Fuera del herbario se sustituyeron carpetas y cartones mojados. Ningún fajo de especímenes se abrió, debido a que esto hubiera causado más daño; además, no hubo espacio ni electricidad para tratar individualmente cada espécimen. Los fajos se agruparon a la sombra, según su condición; los secos se pusieron en cajas para el transporte; los húmedos y empapados en bolsas plásticas. Cajas y bolsas fueron rotuladas, puestas en vehículos y enviadas a varias instituciones que poseen congeladores. Se registró por escrito el destino de cada caja y cada bolsa. No fue posible saber qué porcentaje del material original pudo conservarse después del tratamiento (Pullen Herbarium, 2013).

En Innsbruck (Tirol, Austria), otro desastre prácticamente acabó con el Herbario del Landesmuseum Ferdinandeum (IBF). El Departamento de Historia Natural de este museo fue destruido por una inundación el 6 de agosto de 1985 (Index Herbariorum, 2013). Toda la colección botánica y la biblioteca fueron cubiertas por el agua. Veinte toneladas de material se colocaron en congeladores, esperando el tiempo y los recursos necesarios para una posible restauración. Farasin, Bulfon, Liebel y Tiefenbach (1993) señalan que, afortunadamente, los cerca de 350000 especímenes del herbario se estaban reparando, lo que implicaba liberarlos del lodo y aplicarles técnicas de conservación. El desastre de Innsbruck es revelador, porque un arroyo pequeño e insignificante, el Sill, tributario del río Inn, creció desmesuradamente tras fuertes aguaceros, se desbordó e inundó partes de la ciudad, entre ellas el edificio Zeughaus, en cuyo sótano se hallaban las colecciones de historia natural del Landesmuseum (Museo Estatal). Las pieles de animales quedaron cubiertas de lodo, los especímenes del herbario completamente humedecidos; cajas de insectos flotaron en el agua. Literalmente, mucho se lo llevó la corriente del arroyo. Todavía en la década de 2000 se estaban haciendo restauraciones. Se tomaron medidas inmediatas y exitosas para salvar la colección de insectos y el herbario. Por eso, el curador Gerhard Tarmann tuvo la idea de compartir sus experiencias con todos los colegas posibles y mostrar a otros museos cómo manejar situaciones extremas (Mader, 2004).

Durante la última guerra de los Balcanes (1992-1995), el Museo Estatal de Bosnia-Herzegovina se hallaba a sólo $50 \mathrm{~m}$ del frente que se formó a través de Sarajevo y dividió la ciudad. Pese al peligro, en el museo permaneció parte del personal, que hizo lo posible para mantener limitadas actividades curatoriales y proteger las colecciones. La Biblioteca Nacional fue bombardeaba y se incendió. Los daños en el museo fueron considerables; sin embargo, pudo haber sido peor sin la acción altruista del personal (Mader, 2004).

Tiempo después de la inundación en el Herbario USJ, se tomó la decisión de mantener cerrada la llave maestra del agua del edificio durante las noches y los fines de semana, también en períodos de vacaciones, porque se sabe que la mayoría de tuberías viejas no han sido revisadas ni sustituidas durante años o décadas. En este caso, un dato valioso de los fontaneros es que, aunque la cañería dañada es de acero, en el pasado se usaron uniones de cobre que, con el paso del tiempo, se oxidan y se rompen. Este error lamentable no debió cometerse hace unos 45 años, 
cuando se construyó el edificio. Sin embargo, sabemos que en la década de 1970 no existían medidas para prevenir incendios, inundaciones o terremotos, al menos en edificios pequeños.

En Europa occidental varios herbarios muy prestigiosos están ubicados en sótanos, con sistemas compactadores dentro de una estructura como un bunker a prueba de bombas, inundaciones y otras desgracias. Es el caso del Herbario G (Ginebra, Suiza; B. Hammel, com. pers., 2007) y del Herbario del Museo Botánico de Berlín (B). Este último fue construido después de la Segunda Guerra Mundial, en el período de la Guerra Fría, con el trauma del bombardeo y del incendio de esa magnífica colección científica (con ca. 4 millones de especímenes a inicios de la década de 1940) en la noche del 1 al 2 de marzo de 1943 (Ames, 1944; Hiepko, 1987; Merrill, 1943). Por tanto, considero que no es válido argumentar, como hicieron algunas personas después del accidente en USJ, que una colección científica no debe estar en un sótano. Al contrario, numerosas actividades de una colección científica pueden facilitarse cuando las instalaciones se hallan en un sótano; por ej., el transporte de muebles, especímenes, libros, revistas; la instalación, revisión y reparación de aparatos de aire acondicionado, extractores de humedad y otros equipos, así como el trabajo de fumigación y la protección de la colección contra tornados, huracanes y otras catástrofes naturales relacionadas con fuertes corrientes de viento.

Maurenth Alfaro (com. pers., 2007), médica especialista en prevención de desastres, planteó varias preguntas significativas: ¿Qué otras situaciones de riesgo (aparte de la ruptura de cañerías) se relacionan con el herbario? ¿Cómo disminuir esos riesgos? ¿Existen vías administrativas para manejar emergencias de este tipo en la Escuela de Biología? Como prueba de que el ser humano no aprende bien ciertas lecciones, un nuevo accidente ocurrió el 17 de enero de 2008 , que provocó una considerable fuga de agua hacia el Herbario USJ, por el uso, en la reestructuración de los laboratorios de biología general (planta principal), de una máquina cortadora de ladrillos que requiere de agua. Al respecto, sobresalen varios puntos:

1. La administración ignoró la evidencia indiscutible del 26 de noviembre de 2007, de que el piso del laboratorio 110, que se halla en gran parte sobre la colección de plantas vasculares del herbario, estaba agrietado y también perforado en varias partes por tuberías de agua, gas y corriente eléctrica. Algunas de estas tuberías, por ej. la de gas, ya habían sido cortadas y eliminadas, de modo que cualquier fuga de agua en ese laboratorio iba directamente hacia la colección de dicotiledóneas del herbario.
2. En esta ocasión el accidente no fue tan grave como en noviembre de 2007, debido a que minutos antes de que se iniciara el trabajo fui informado de que se utilizaría una máquina corta-ladrillos que requiere de agua. Por intervención directa de Virginia Solís, Directora de la Escuela de Biología, el trabajo se suspendió inconcluso al cabo de unos cinco minutos de haberse iniciado. En ese tiempo cayeron al herbario no solamente torrentes de agua sucia, sino también escombros de arena y cemento, evidencia indudable de que el piso del laboratorio estaba fuertemente perforado. Durante dos días fue necesario volver al mismo drama de noviembre de 2007: Secar el agua del techo del compactador y del piso, revisar y sacar todas las carpetas de especímenes que se mojaron (al menos 50, con unos 500 especímenes), solicitar extractores de humedad, reparar especímenes dañados y sustituir materiales dañados. Parece absurdo que se cometan errores como éste, cuando la experiencia reciente indicaba qué ocurriría exactamente. A menudo las recomendaciones que se basan en la observación y la experiencia son ignoradas sistemáticamente por las personas que toman las decisiones.

3. Era fácil deducir que ese laboratorio sería un peligro constante para el herbario, a menos que se tomaran medidas de seguridad muy estrictas. Después de varias sugerencias que fueron planteadas, la administración decidió no permitir el uso de máquinas que requieren de agua; el piso se cubrió con cerámica impermeable al agua y en una esquina del laboratorio se habilitó un canal de escape de aguas derramadas. En un laboratorio de biología se trabaja a menudo con líquidos, por lo que las fugas de agua son predecibles. Asegurar la integridad de las colecciones científicas es una responsabilidad fundamental de toda institución universitaria. Sin embargo, en general, son personas concretas, con formación docente y científica, no instituciones, las que hacen posible que durante generaciones una colección científica crezca, mejore y sea cada vez más útil y más valiosa, incluso para personas ajenas a las labores científicas.

Newey, Lepschi y Croft (2006) prepararon un plan de recuperación de desastres de un herbario australiano, que es un ejemplo de organización que muchos herbarios del mundo deberían tener. Los autores indican que este plan ayuda a reducir el daño provocado por un desastre al ofrecer una guía para una respuesta eficaz a una situación de emergencia. Ellos proponen medidas de A) Prevención y preparación, B) Reacción, C) Recuperación, D) Restauración y rehabilitación. Los objetivos del plan son reducir el 
daño a las colecciones, recuperar y reparar todos los especímenes dañados y hacer que el herbario vuelva a funcionar normalmente.

El plan de emergencia favorece el cumplimiento de estos objetivos, porque provee de una guía para lograr una respuesta rápida y eficaz a una emergencia, buena comunicación, un personal bien entrenado, disposición de equipo y materiales apropiados y asistencia de otras organizaciones. Un punto crucial es que la seguridad de las personas es lo primero; por tanto, el rescate de las colecciones dañadas debe proceder después de que personas lesionadas o heridas han sido atendidas y el edificio ha sido declarado seguro (Newey et al., 2006).

En USJ nunca hubo un plan tan ambicioso como el descrito por Newey et al. (2006); sin embargo, lo que ocurrió tras la inundación fue exactamente lo que debía ocurrir según un plan estructurado: la reacción fue inmediata; numerosas personas, conscientes de la importancia del herbario, colaboraron haciendo tareas prioritarias, guiadas por no más de dos personas que sabían exactamente qué debía hacerse. Se tomaron medidas de seguridad, como desconectar la corriente eléctrica al inicio del proceso (debido al exceso de agua), y se recibió ayuda logística y tecnológica apropiada, sobre todo para disponer de mayor número de extractores de humedad. Además, se hizo un trabajo persistente y detallado de dos semanas hasta asegurar que todos los especímenes catalogados habían sido salvados y, finalmente, se ideó un plan para restaurar todo el material científico dañado. Se dio prioridad al trabajo de restaurar toda la colección de dicotiledóneas; no solamente los especímenes dañados por agua, sino también los que tenían piezas sueltas o cartulina dañada, entre otros detalles.

Al contrario de lo señalado en el plan australiano, nunca hemos tenido planos detallados del edificio, que indiquen dónde están las colecciones de especímenes, los libros más valiosos, las luces de emergencia, los aparatos eléctricos y electrónicos y las salidas de emergencia. Por tanto, es conveniente identificar los peligros potenciales para las colecciones (esto es, prevenir), hacer los cambios de infraestructura que sean necesarios, colocar rótulos apropiados y tener siempre a disposición los números de teléfono de las personas y las organizaciones que pueden prestar su ayuda en caso de emergencia; por ejemplo, Bomberos, Cruz Roja y, en el caso de USJ, la Sección de Mantenimiento y Construcción y la Sección de Seguridad y Tránsito de la Universidad de Costa Rica.

La conciencia sobre el peligro que corren los museos y otras colecciones valiosas ante inundaciones, incendios, acciones terroristas y otras desgracias motivó a numerosos académicos europeos y norteamericanos a crear una organización que aporta ideas para mejorar la seguridad y el buen desempeño del patrimonio de los museos, que trasciende fronteras nacionales. Uno de los objetivos más importantes del Consejo Internacional de Museos (ICOM, 2013) es mitigar desastres en colecciones patrimoniales de ciencias, artes, letras e historia. En la década de 2000 hubo un número considerable de conferencias internacionales sobre desastres y accidentes que pueden causar grandes pérdidas en museos y bibliotecas. En Europa sobresale el esfuerzo de los países de habla germana (Alemania, Austria y Suiza), donde un comité mixto organiza un simposio cada tres años. Debido al impacto de las inundaciones de agosto de 2002 en algunas regiones de Alemania, Austria y República Checa, el comité discutió prioritariamente este tema; sin embargo, en el simposio no solamente se discute sobre inundaciones desastrosas, sino también sobre incendios, robos, disminución de riesgos y protección del patrimonio cultural. Según la información aportada por ICOM (2013), en América solamente Canadá y EE. UU. han organizado conferencias sobre seguridad en museos, mientras que los países de América Latina permanecen al margen.

Las conferencias sobre prevención de desastres en museos, realizadas en la década de 2000, revelan que no existe una regla de oro del manejo de catástrofes, sino que cada museo tiene que desarrollar un plan de emergencia propio, que considere la naturaleza específica tanto del edificio como de la colección. La obra editada por Mader (2004) resume claramente la experiencia de USJ: No hace falta un río para provocar una inundación; una cañería rota puede tener exactamente las mismas consecuencias. Yo puedo agregar que no hace falta una catástrofe, tal como un terremoto de gran magnitud, porque un temblor o el paso del tiempo puede provocar la ruptura de una cañería de agua potable, vieja y descuidada, para dañar irreversiblemente una colección científica que ha costado decenas o cientos de años y el aporte valiosísimo e irrepetible de numerosas personas: científicos, técnicos, estudiantes y voluntarios.

\section{Resumen de la experiencia obtenida en el Herbario de la Universidad de Costa Rica (USJ)}

En caso de inundación por ruptura de tuberías de agua $u$ otros accidentes afines, se recomienda poner en práctica los siguientes pasos:

1. No perder el control y no pensar que el daño es irreparable. Buscar ayuda y actuar de inmediato.

2. Cerrar de inmediato la llave maestra de la tubería dañada. Llamar a los fontaneros competentes para reparar el daño cuanto antes. 
3. Suspender la corriente eléctrica en la parte afectada del edificio. Tener a mano linternas.

4. Tener a mano escobas, fregones, trapos y recipientes para recoger toda el agua derramada posible, para impedir que siga cayendo en el área de las colecciones científicas.

5. Detenida la fuga de agua, iniciar la extracción del agua empozada sobre gabinetes de las colecciones. Tener a mano trapos de tela absorbente y abundante papel periódico para facilitar la absorción de la humedad retenida en las superficies. Enseguida sacar toda el agua caída sobre el piso con escobas, fregones, trapos y recipientes apropiados.

6. Superado el goteo y el exceso de humedad en muebles y pisos, conectar de nuevo la corriente eléctrica, cerrar las puertas y poner al máximo los aparatos de aire acondicionado y los extractores de humedad disponibles. Usar cables de extensión para conectar los aparatos a diferentes circuitos eléctricos; de lo contrario el sistema eléctrico puede colapsar. Sacar a diario el agua recogida por los extractores.

7. Iniciar sin demora una revisión minuciosa del material científico en los sectores afectados. Dar prioridad a los especímenes más húmedos. Secar gotas y pozos de agua de superficies y especímenes; poner papel periódico entre los especímenes mojados y sacarlos de inmediato para ponerlos en una secadora de plantas.

8. Dejar especímenes menos húmedos en el herbario, porque con la tecnología de extracción de humedad allí están más seguros, sobre todo en zonas tropicales. Secar el exceso de humedad con trapos, poner papel periódico bajo y entre los especímenes y dejarlos expuestos, sin cerrar gabinetes para mejorar el efecto desecante de los extractores de humedad y del aire acondicionado.

9. Tomar los especímenes húmedos que no han sido atacados por hongos, ponerlos en prensas y llevarlos a una secadora de plantas. Revisar día a día los ejemplares tratados, tanto en la secadora como en el herbario. Asegurarse en todos los casos de cambiar todo el papel periódico húmedo por papel seco dentro del herbario. Este trabajo detallado hace la mayor diferencia entre recuperar y perder especímenes.

10. Tener una reserva de alcohol al 95\%. Si aparecen hongos, retirar de inmediato todos los especímenes afectados (en muchos casos pueden ser varias carpetas contiguas hasta todo el material de una o más gavetas); sacar del herbario y llevar a un sitio de trabajo cómodo; colocar especímenes ligeramente inclinados sobre papel periódico; verter abundante alcohol en toda la superficie afectada por hongos. Al estar inclinado el espécimen, el alcohol arrastra la materia fúngica. Limpiar con tela o papel absorbente cualquier mancha o retículo residual de hongos; cubrir especímenes con papel periódico seco hasta absorber el exceso de alcohol (para evitar el goteo en la secadora), poner entre cartones, prensar, atar y poner en la secadora de plantas en un nivel bajo o medio de calor. Revisar los especímenes de cada prensa diariamente.

11. Separar el material ya seco que está dañado o sucio y llevarlo al cuarto de montaje para ser reparado.

12. Superada la emergencia, revisar el techo de las instalaciones del herbario y el piso en busca de grietas, perforaciones y tuberías, que deben sellarse a prueba de agua. Construir y probar canales de escape de agua, tanto en el piso superior como en el de la colección.

13. En el herbario usar sólo tinta permanente para escribir etiquetas, números de herbario y correctores de taxonomía. No usar lápices (con el tiempo el grafito se vuelve borroso, especialmente en papel y cartón de baja calidad; esto empeora en contacto con agua), bolígrafos comunes ni tintas demasiado líquidas. Además, imprimir etiquetas con una impresora de alta calidad y una buena impresión.

14. Mantener siempre en gabinetes y gavetas cerrados herméticamente los especímenes montados y catalogados del herbario, así como el material recibido en préstamo, todos los tipos, los especímenes únicos (sin duplicados), los libros y las revistas más valiosos. Reparar cuanto antes las cerraduras dañadas en los gabinetes, para prevenir la entrada de humedad, hongos e insectos.

15. Proteger siempre con cubiertas impermeables al agua los equipos de cómputo, de óptica y otros aparatos electrónicos delicados. Asegurarse de apagar todos los aparatos eléctricos y electrónicos sin uso dentro de la colección.

16. Si no hay personas en las colecciones durante las noches, los fines de semana y las vacaciones, en esos períodos mantener cerrada la llave maestra del agua potable del edificio (sobre todo si se sabe, o al menos se sospecha, que la cañería podría ser defectuosa o estar dañada).

17. Las tuberías subterráneas y aéreas de agua potable, aguas servidas y gas deberán estar, idealmente, fuera del área de las colecciones científicas.

Las recomendaciones anteriores son válidas sobre todo para un herbario relativamente pequeño (USJ 
posee poco más de 100000 especímenes registrados y varios miles sin registrar), que ha sido afectado en parte y que está ubicado en un piso inferior o intermedio de un edificio relativamente pequeño (no más de cinco niveles). También son válidas para herbarios más grandes (hasta ca. 500 mil especímenes). Sin embargo, un evento catastrófico de grandes consecuencias (terremoto, huracán, tornado, bombardeo) por lo general hace imposible recuperar íntegramente una colección científica, a menos que ésta se halle en el interior de una infraestructura protectora especial.

\section{AGRADECIMIENTOS}

A todas las personas que prestaron su valiosa colaboración para rescatar todos los especímenes dañados de USJ, en especial a las asistentes Diana Leiva, Maricela PizarroPorter, Wendy Solís H., Gisella Fernández, Melania Fernández y Sirlene Víquez. En las primeras horas de la emergencia fue crucial el apoyo logístico de Daniel Briceño, Viviana Lang, Federico Bolaños y Elmer García. También el esfuerzo de numerosos estudiantes (como Nancy Orias $\mathrm{H}$. y Esteban Biamonte) y administrativos hizo posible rescatar lo que otros creían perdido para siempre; lamentablemente no es posible mencionar aquí todos los nombres. Agradezco sinceramente a Mario A. Blanco (antes FLAS, ahora USJ) la información que me ofreció, la motivación para escribir este texto, así como la revisión y corrección de la versión inglesa.

\section{REFERENCIAS}

Ames, O. (1944). Destruction of the Schlechter Herbarium by bombing. American Orchid Society Bulletin, 13(4), 105-106.

Barquero, H. (1982). José María Orozco; un sabio en el mundo de las plantas. San José: Ministerio de Cultura, Juventud y Deportes.

Clark, S.H. (1986). Preservation of herbarium specimens: An archive conservator's approach. Taxon, 35, 675-682.

Hiepko, P. (1987). The collections of the Botanical Museum Berlin-Dahlem (B) and their history. Englera, 7, 219-252.
ICOM. (2013). International Council of Museums. Disaster Relief for Museums. Conferences. Recuperado de http://archives.icom.museum/disaster_relief/conferences.html

Index Herbariorum. 2013. Tiroler Landesmuseum Ferdinandeum. Herbarium IBF. Recuperado de http://sweetgum. nybg.org/ih/herbarium.php?irn=126158 [2 de septiembre de 2013]

Farasin, K., Bulfon, A., Liebel, G. \& Tiefenbach, M. (1993). Naturschutzgebiete Österreichs. Band 3: Tirol, Vorarlberg. Monographien Bd. $38 \mathrm{C}$. Wien: Bundesministerium für Umwelt, Jugend und Familie. Recuperado de http://www. umweltbundesamt.at/publikationen/publikationssuche/ publikationsdetail/?\&pub_id=478

Mader, S. (Ed.). (2004). Proceedings of the International Congress Catastrophes and Catastrophe Management in Museums, Sarajevo, 17-21 April 2001. Innsbruck: Tiroler Landesmuseum Ferdinandeum / Sarajevo, Zemaljski Muzej Bosne i Hercegovine. [Resumen en inglés y extensa reseña en alemán por Friebe, J.-G. 2005. Virtual Library Museen. Recuperado de http://bestiarium.net/VL-museen/]

Merrill, E.D. (1943). Destruction of the Berlin Herbarium. Science, 98(2553), 490-491.

Metsger, D.A. \& Byers, S.C. (Eds.) (1999). Managing the modern herbarium; an interdisciplinary approach. Vancouver: E. Wolf Publ.

Morales, C.O. (2006). Un herbario de Costa Rica llega a 75 años. Lankesteriana, 6(2), 25-28.

Morales, C.O. (2012). El Herbario USJ de Costa Rica: trayectoria y contribuciones. Revista de Biología Tropical, 60(4), 1641-1648.

Morales, C.O. \& Villalobos T., N. (2004). Tipos de plantas vasculares en el Herbario de la Universidad de Costa Rica (USJ). Lankesteriana, 4(3), 187-208.

Newey, A., Lepschi, B. \& Croft, J. (2006). A Disaster Recovery Plan for the Australian National Herbarium, Canberra. Centre for Plant Biodiversity Research (CPBR). Recuperado de http://www.anbg.gov.au/cpbr/disaster-plan/

Pullen Herbarium (MISS). (2013). Gulf Coast Research Lab., Ocean Springs, Mississippi. Recuperado de www.mcsr.olemiss. edu/herbarium/

RSN. (2007). Boletín [de la] Red Sismológica Nacional (RSN: UCRICE). Resumen de la actividad sísmica en Costa Rica durante el mes de noviembre 2007. Recuperado de http:// www.rsn.ucr.ac.cr/index.php/en/publicaciones/mns

Touw, M. \& Kores, P. (1984). Compactorization in herbaria: planning factors and four case studies. Taxon, 33, 276-287. 